\title{
"É SOM DE PRETO E FAVELADO": O CARÁTER DIASPÓRICO, GLOBAL E LOCAL DO FUNK
}

\author{
Réia Sílvia Gonçalves Pereira ${ }^{1}$
}

\begin{abstract}
Resumo
Associado à juventude negra das camadas populares brasileiras, o caráter diaspórico do funk revela-se por meio da música, do corpo e do estilo. O funk é compreendido como uma intrigante expressão da cultura popular. Para embasar tal argumento, este artigo ampare-se nas conceituações de Stuart Hall sobre a diáspora negra e nas reflexões de Néstor García Canclini sobre culturas híbridas.

Palavras-chave: Cultura de massa, cultura popular, funk.
\end{abstract}

\section{Abstract}

Associated with black youth Brazilian popular groups, the diasporic character of funk reveals itself through music, body and style. The culture of funk is understand as a special way of expression of popular culture. To support this argument, we use conceptualizations of Stuart Hall on the black diaspora and reflections of Nestor Garcia Canclini on hybrid cultures.

Keywords: Mass culture, popular culture, funk.

\section{Introdução}

"É som de preto e favelado, mas quando toca ninguém fica parado, tá ligado?"2 A simplicidade direta dos versos da música composta pelos até então adolescentes Almickar e Chocolate revela uma peculiaridade sobre o funk, sua associação com as camadas populares e com a cultura popular negra. Assim, a intenção desse artigo é analisar a trajetória do ritmo musical e sua difusão no Brasil, atentando para os seus aspectos globais e locais, que permitem que a manifestação musical seja reconhecida, compartilhada e reproduzida por uma parcela significativa de jovens negros e pobres.

\section{Que cultura, que popular e que negro da cultura popular negra?}

Classificar o funk como manifestação da cultura popular negra leva ao questionamento sobre o sentido assumido por tal qualificação. Para início de discussão, as três palavras da expressão "cultura popular negra" possuem sentidos controversos e conflituosos.

O próprio conceito de cultura está longe de ter uma definição consensual. No entanto, para analisar os sentidos simbólicos de uma manifestação musical como o funk, amparo-me

\footnotetext{
${ }^{1}$ Mestranda do programa de Ciências Sociais da Universidade Federal do Espírito Santo (UFES), especialista em Questão Social e Políticas Públicas (UFES), graduada em Comunicação Social (UFES).

${ }^{2}$ Almickar e Chocolate. Funk das antigas. Disponível em: http://letras.mus.br/amilcar-e-chocolate/162677/.
} 
na conceituação de Clifford Geertz (1978). O autor emprega um caráter dinâmico à concepção de cultura, ao defini-la como teias de significados tecidas pelo homem às suas ações. Por essa perspectiva, a cultura seria um complexo enredo de relações simbólicas contextualizadas:

A cultura não é um poder, algo ao qual podem ser atribuídos casualmente os acontecimentos sociais, os comportamentos, as instituições ou os processos; ela é um contexto, algo dentro do qual eles (os símbolos) podem ser descritos de forma inteligível - isto é, descritos com densidade (GEERTZ, 1978, p. 24).

Observe-se que Geertz concebe a cultura como um processo aberto à transformação. A teia é formada pelos sentidos interpretados, que novamente recebem novos significados, numa conformação complexa e multidimensional. Desta forma, a cultura é inexoravelmente pública, porque sua condição depende necessariamente do compartilhamento dos sentidos e, dessa partilha de significados, se estabelece o contexto proposto pelo autor.

Neste prisma, a cultura seria o elemento organizador da vida, uma forma de controle que possibilitaria a conformação de mecanismos que convencionam certos modos de comportamentos e de apreensão de mundo. "Tornar-se humano é tornar-se individual e nós nos tornarmos individuais sob a direção de padrões culturais, sistemas de significado criados historicamente através dos quais damos forma, ordem objetivo e direção as nossas vidas" (p. 64).

Remeto-me aos conceitos de teias de significados por remeterem a uma definição ampla de cultura. Em Geertz, cultura refere-se a um mundo regido por símbolos, cujos sentidos se efetuam em relações, que, por serem contextualizadas, se fazem múltiplas. Produzimos diversas formas de ser e de viver, cujos sentidos só são compreensíveis por intermédio das culturas, das quais fazemos parte.

\section{O popular da cultura}

Se, como dito, a conceituação de cultura é um terreno movediço, quando o termo é acrescido do adjetivo "popular", sua definição se torna ainda mais árdua. De fato, a enunciação da expressão “cultura popular” já revela uma tensão inerente. Para Roger Chartier (1995), o sentido corrente de popular encontra-se relacionado com seu oposto, o erudito.

Peter Burke (1989) destaca que a polarização de sentidos entre erudito e popular data do século XVII, quando estudiosos europeus demarcaram o que seriam as manifestações das classes abastadas em oposição às práticas mais difundidas. Dessa época é que surge a classificação de folclore, ou "o saber do povo". 
A partir do século XIX, sob influência do Romantismo, estabelece-se a tendência à idealização da forma de vida das regiões rurais europeias. Popular ganhava a conotação de puro, natural.

Mas foi no século XX que a categoria tornou-se cada vez mais controversa. Mikhail Bakhtin (1993) é considerado um marco nos estudos da cultura popular. O autor elabora uma teorização do cômico e da cultura popular da Idade Média e do Renascimento, destacando que o burlesco e a troça, características das manifestações populares, configuram-se como uma visão de mundo peculiar das camadas mais pobres. Tal visão de mundo, no entanto, não pode ser definida como autônoma, porque também mantém um permanente e dinâmico contato com a cultura oficial, influenciando e sendo influenciada por ela. Em consequência, o que se qualifica de "erudito" e o "popular" está em permanente processo de ajustes e desajustes (BAKHTIN, 1993).

Mas talvez tenha sido o historiador Roger Chartier (1995) quem criticou com mais ênfase o sentido binário e distintivo adquirido pelo termo no pensamento no europeu, que concebe ora como dependente do universo simbólico da cultura dominante, ora como um universo autônomo e fechado:

O primeiro (sentido) no intuito de abolir toda forma de etnocentrismo cultural, concebe a cultura popular como um sistema simbólico coerente e autônomo, que funciona segundo uma lógica absolutamente alheia e irredutível à da cultura letrada. O segundo, preocupado em lembrar a existência das relações de dominação que organizam o mundo social, percebe a cultura popular em suas dependências e carências em relação à cultura dos dominantes. Temos, então, de um lado, uma cultura popular que constitui um mundo à parte, encerrado em si mesmo, independente, e, de outro, uma cultura popular inteiramente definida pela sua distância da legitimidade cultural da qual ela é privada (CHARTIER, 1995, p.179).

Em síntese, o que se configura como popular é a apropriação e "produção de sentido" por parte dos setores não hegemônicos. Entretanto, o importante seria identificar como se opera esse relacionamento entre as formas impostas, de um lado, e as táticas agenciadas pelos segmentos subalternos, por outro. Para o autor haveria um espaço entre as "injunções constrangedoras" e a "recepção".

Inútil querer identificar a cultura popular a partir da distribuição supostamente específica de certos objetos ou modelos culturais. O que importa, de fato, tanto quanto sua repartição, sempre mais complexa do que parece, é sua apropriação pelos grupos ou indivíduos. Não se pode mais aceitar acriticamente uma sociologia da distribuição que supõe implicitamente que à hierarquia das classes ou grupos corresponde uma hierarquia paralela das produções e dos hábitos culturais (Idem).

\section{Cultura popular e globalização: cultura híbrida?}


Se, como salienta Chartier, a concepção de cultura popular deve ser contextualizada, é preciso destacar o sentido adquirido pela categoria na contemporaneidade, marcada pela globalização e expansão do consumo de bens culturais.

Mas para estes - habitantes locais mais por sina que por opção - a desregulamentação, a dissipação de redes comunitárias e a forçosa individualização do destino implicam agruras bem distintas e sugerem estratégias bem diferentes (Idem, p. 109).

Néstor García Canclini (1995), em “Culturas populares no capitalismo”, advoga que essa confluência de universos culturais se estabelece nos setores subalternos como um processo, em que, se por um lado, não pode negar as assimetrias e hierarquizações, por outro lado, há que se levar em conta o processo não apenas de absorção e reprodução dos referenciais simbólicos, mas também de transformação e criação dessas referências, conformando assim um universo heterogêneo, não sendo mais possível conceber a categoria em seu sentindo singular. O que teríamos, para Canclini, é uma diversidade de culturas populares.

“[As] Culturas populares se constituem por um processo de apropriação desigual dos bens econômicos e culturais de uma nação ou etnia, por parte dos seus setores subalternos, e pela compreensão, reprodução e transformação real e simbólica das condições gerais e específicas do trabalho (CANCLINI, 1995. p. 12).

Em outro trecho de "Culturas populares do capitalismo", Canclini sintetiza:

A especificidade das culturas populares não deriva apenas do fato de que a sua apropriação daquilo que a sociedade possui seja menor e diferente; deriva também do fato de que o povo produz no trabalho e na vida formas específicas de representação, reprodução e reelaboração simbólica de suas relações sociais (CANCLINI, 1995. p. 57).

Trazendo as reflexões sobre globalização e fluxos culturais para o cenário latinoamericano, Canclini desenvolve o conceito de culturas híbridas. Para o autor, no contexto global, o que se configura é a intensificação das mesclas interculturais possibilitando o surgimento de culturas muito mais abertas às "influencias externas". Essa radicalização da permeabilidade entre as fronteiras estabelece-se porque, ao contrário de visões essencialistas, as culturas são, e sempre foram, inexoravelmente permeáveis e cambiáveis.

A ênfase na hibridização não só encerra a pretensão de estabelecer identidades "puras" ou "autênticas". Mas também, põe em evidência o risco de delimitar identidades locais autocontidas, ou que tentem afirmar-se como radicalmente opostas à sociedade nacional ou à globalização. Quando se define uma identidade mediante um processo de abstração de características (língua, tradições, certas 
condutas estereotipadas) se tende freqüentemente a desprender essas práticas da história de misturas em que se formaram. Como conseqüência, absolutiza-se um modo de entender a identidade e excluem-se as maneiras heterodoxas de falar a língua, fazer música ou interpretar as tradições. Acaba-se, em suma, obturando a possibilidade de modificar a cultura e a política (CANCLINI, 2006, p.17).

Stuart Hall (2003) reconhece a dialética e hierarquizações entre cultura erudita e popular, mas sugere que a discussão se desloque para o espaço em que se estabelece a cultura popular. Espaço esse caracterizado por uma relação mais complexa do que uma simples disputa de dominação e assimilação. Mais do que uma relação de disputa entre opostos, entre o popular e o erudito ocorre uma relação circular, por vezes contraditória. Um diálogo, revelando um complexo processo de apropriação, reconhecimento, rejeição, adesão e resistência.

\begin{abstract}
A hegemonia cultural nunca é uma questão de vitória ou dominação pura (não é isso que o termo significa); nunca é um jogo cultural de perde-ganha, sempre tem a ver com a mudança no equilíbrio de poder nas relações de cultura, trata-se sempre de mudar as disposições e configurações do poder cultural e não se retirar dele. A questão importante é o ordenamento das diferentes morais estéticas, das estéticas sociais, os ordenamentos culturais que abrem a cultura para o jogo do poder, e não um inventário do que é alto versus o que é baixo em um momento específico (HALL, 2003, p.78).
\end{abstract}

Hall destaca que é no senso comum que as referências simbólicas são interpretadas. E é nesta arena, a do senso comum, cada vez mais marcado pela indústria cultural, que as concepções do que é popular ou erudito são categorizadas enquanto tais.

[O papel] da cultura popular é o de fixar a autenticidade das formas populares, enraizando-as nas experiências das comunidades populares das quais elas retiram o seu vigor e nos permitindo vê-las como expressão de uma vida social subalterna especifica, que resiste a ser constantemente reformulada enquanto baixa e periférica (HALL, 2003, p.78).

Nesta perspectiva, a concepção de cultura popular se estabelece em um âmbito profundamente simbólico, ancorado em representações e abstrações, por meio das quais nos reconhecemos e nos identificamos:

Essa cultura popular, mercantilizada e estereotipada como é frequentemente, não constitui, como às vezes pensamos, a arena onde descobrimos quem realmente somos, a mente mítica. É um teatro de desejos populares, um teatro de fantasias populares. É onde descobrimos e brincamos com as identificações de nós mesmos, onde somos imaginados, representados, não somente para o público lá fora, que não entende a mensagem, mas também para nós mesmos pela primeira vez (HALL, 2003, p. 348). 


\title{
O negro da cultura popular
}

É neste contexto complexo, diverso e contraditório no qual se configura a cultura popular que as referências relacionadas à população negra se inserem. Como adianta Stuart Hall, a cultura popular negra é, em si, contraditória.

Para Gilroy (2001), grande parte das representações sobre o que seja a cultura negra advém das manifestações da diáspora africana. $O$ termo caracteriza processo de "reconstrução" das referências culturais africanas em contextos de dominação estrangeira ensejada pela escravidão e, mais recentemente, pela migração. Por essa perspectiva, a identidade diaspórica estaria em um movimento permanente de tradução e hibridização cultural.

\begin{abstract}
Sob a chave da diáspora nós poderemos então ver não a raça, e sim formas geopolíticas e geoculturais de vida que são resultantes da interação entre sistemas comunicativos e contextos que elas não só incorporam, mas também modificam e transcendem [...] o conceito de espaço é em si mesmo transformado quando ele é encarado em termos de um circuito significativo que capacitou as populações dispersas a conversar, interagir e mais recentemente até a sincronizar significativos elementos de suas vidas culturais e sociais (GILROY, 2001, p. 21).
\end{abstract}

Nesta esteira, para Stuart Hall (2003), com o fim da era colonial, o conflito não está mais na relação colônia-metrópole, e sim em suas assimetrias internas e em sua relação com os processos globais.

Essa perspectiva é dialógica, já que é tão interessada em como o colonizado produz o colonizador quanto vice-versa: a co-presença, interação, entrosamento das compreensões e práticas frequentemente no interior de relações de poder radicalmente assimétricas (HALL, 2003, p. 31-32).

Dessas relações assimétricas, estabelece-se uma contranarrativa por meio de manifestações marcadas pelo caráter contraditório e impoluto; mas que, ao mesmo tempo, conseguem ser reconhecidas como próprios da cultura negra.

Não importa o quão deformadas, cooptadas e inautênticas sejam as formas como os negros e as tradições e comunidades negras pareçam ou sejam representadas na cultura popular, vê-se ainda figuras e repertórios, aos quais a cultura popular recorre, as experiências que estão por trás delas. Em sua expressividade, sua musicalidade, sua oralidade e na sua rica, profunda e variada atenção à fala; em suas inflexões vernaculares e locais; em sua rica produção de contranarrativas; e, sobretudo, em seu uso metafórico do vocabulário musical, a cultura popular negra tem permitido trazer à tona, até nas modalidades mistas e contraditórias da cultura popular mainstream, elementos de um discurso que é diferente - outras formas de vida, outras tradições de representação (HALL, 2003, p. 342). 
Hall enumera os três elementos do repertório da tradição diaspórica negra forjados no embate contra a hegemonia cultural. São eles: o estilo, "que os críticos culturais da corrente dominante muitas vezes acreditam ser uma simples casca, uma embalagem" (p. 342); a música, que se revela uma forma de afirmação ante um mundo centrado na escrita; e o corpo, muitas vezes, o único capital cultural das comunidades marcadas pela diáspora. Afirma Stuart Hall que, diante da cultura hegemônica, tal repertório foi sobredeterminado:

Existem aqui questões profundas de transmissão e herança cultural, de relações complexas entre as origens africanas e as dispersões irreversíveis da diáspora; questões que não vou aprofundar aqui. Mas acredito que esses repertórios da cultura popular negra - uma vez que fomos excluídos da corrente cultural dominante eram frequentemente os únicos espaços performáticos que nos restavam e que foram sobredeterminados de duas formas: parcialmente por suas heranças, e também determinados criticamente pelas conduções diaspóricas nas quais as conexões foram forjadas. A apropriação, cooptação e rearticulação seletivas de ideologias, culturas e instituições europeias, junto a um patrimônio africano (HALL, 2003, p. 342).

No entanto, o contexto contemporâneo global ${ }^{3}$ possibilita uma maior valorização e visibilidade desse repertório. Tal valorização se estabelece pela própria ambivalência do período em relação a um certo "fascínio" pela diferença e pela diversidade e pelas lutas culturais da diferença:

Dentro da cultura, a marginalidade, embora permaneça periférica em relação ao mainstream, nunca foi um espaço tão produtivo quanto é agora, e isso não é simplesmente uma abertura, dentro dos espaços dominantes, a ocupação dos de fora. É também o resultado de políticas culturais da diferença, de lutas em torno da diferença, da produção de novas identidades e do aparecimento de novos sujeitos no cenário político e cultural. Isso vale não somente para a raça, mas também para outras etnicidades marginalizadas, assim como o feminismo e as políticas sexuais no movimento de gays e lésbicas, como resultado de um novo tipo de política culturais (Ibidem, p. 338).

\section{Voltando ao funk}

Tendo em perspectiva os apontamentos apresentados, advogo que o funk é uma das manifestações da diáspora africana no Brasil. Como argumento, destaco a trajetória do gênero no país. Florescido nas favelas cariocas, o funk nacionalizou-se, numa expansão que teve como protagonista uma parcela da juventude urbana, pobre e negra (DAYRELL, 2001).

De acordo com Hermano Vianna $(1987,1998)$, o funk originou-se do soul, que é a união do rhythm and blues e da música protestante negra. A palavra funky se referia a termos como mal-cheiroso e estranho. No entanto, a gíria foi ressignificada pela população afrodescendente, recebendo uma conotação de contestação e ironia.

\footnotetext{
${ }^{3}$ Hall utiliza o termo "pós-moderno global".
} 
A partir da década de 1970, o funk ingressa no Brasil surpreendentemente por meio das casas de show da Zona Sul do Rio de Janeiro. Eram os "bailes da pesada", que reuniam centenas de participantes. No entanto, os bailes foram transferidos para o subúrbio, onde eram realizados "a cada fim de semana em um bairro diferente" (VIANNA,1987).

$\mathrm{Na}$ década de 1980, o ritmo chega aos morros cariocas, agora impulsionado pelo sucesso do estilo de rap Miami, que trazia músicas mais erotizadas, batidas graves, acentuadas e mais rápidas. Nessa época, ficaram famosos os bailes realizados pelos DJs, em que as músicas cantadas em inglês recebiam "novas letras" aportuguesadas. "[...] teríamos uma primeira forma de apropriação criativa, que resulta num produto obviamente híbrido: músicas americanas tocadas em versões instrumentais com refrões gritados pelo público dos Bailes em português" (SÁ, 2009, p.6).

No final dos anos de 1980, surgem as primeiras produções brasileiras, ensejadas pelos MCs. A nacionalização do ritmo se estabelece na década de 1990, quando o gênero ganha visibilidade nos meios de comunicação. Tal visibilidade, no entanto, revela uma ambigUidade. De um lado, com a incorporação de alguns funkeiros ao sistema de gravadoras, por outro lado, com a divulgação de notícias que associavam o ritmo e os bailes à criminalidade.

Seguiu-se um enorme debate e a associação entre os bailes funk e a violência atravessou a década de 90 , presente no imaginário da mídia, das autoridades policiais e da classe média, com medidas de repressão cartas nos jornais e ondas de demonização do fenômeno na mídia. O que em nada diminuiu a orça do funk na periferia do Rio de Janeiro (SÁ, 2007, p. 12).

Juarez Dayrel (2005) afirma que o funk enquanto estilo de vida juvenil se define em meados década de 1990. Até então, os jovens não se identificavam como "funkeiros". A partir do sucesso dos Mestres de Cerimônia (MCs), nasce o funk como um "marco identitário" e fator de socialização para os segmentos juvenis:

\footnotetext{
Essas considerações indicam que a identidade que esses jovens constroem como funkeiros é fluida e efêmera, uma imbricação com elementos simbólicos apropriados da cultura popular, da indústria cultural em geral, como manifestação cultural híbrida. Essa identidade apresenta-se como uma fronteira provisória e móvel, operando a partir de múltiplos registros na construção mais ampla de uma identidade desses sujeitos como jovens. Podemos dizer que o funk é parte de determinado estilo de vida juvenil, um marco identitário que contribui para que esses jovens possam vivenciar e se afirmar como sujeitos numa determinada fase da vida (DAYRELL, 2002, p.133).
} 
Já consolidado nos anos 2000, o funk ingressa numa fase marcada por músicas com conotação erótica, cujas músicas giram em torno da conquista sexual. Há o surgimento dos chamados "bailes do prazer", nos quais ganham visibilidade a performance de exaltação à masculinidade, ao homem conquistador e infiel. Como resposta, as mulheres passam a produzir e apresentar suas próprias músicas, em que afirmam a independência e liberdade sexual.

\section{O estilo, o corpo e a música: o caráter diaspórico do funk}

Assim como explica Stuart Hall, o repertório da cultura popular negra se manifesta por meio do estilo, do corpo e da música. No funk, esse três elementos foram "traduzidos" de uma forma muito peculiar e, diria mesmo, evidente.

O fato é que, atualmente, com todas as misturas e reinterpretações, o funk se estabelece como um grupo de estilo e marco identitário marcado pela exaltação à sexualidade, cujo código mais difundido é a música (DAYRELL, 2002; VIANNA, 1987; HERSCHMANN, 2000).

Talvez a expressividade máxima do funk se apresente nos bailes. Ressalvando as especificidades de cada contexto, Juarez Dayrell e Hermano Vianna observam que as festas funk são marcadas por um caráter ritual que remete à catarse e ao hedonismo:

O baile é um ritual que se repete no tempo e no espaço: o encontro prévio com a galera, a euforia provocada pela música e pela dança, os movimentos da massa, as montagens e seus refrões incansavelmente repetidos, tudo contribui para um clima de excitação, fazendo da festa a pura diversão, sem qualquer outra finalidade. [...] Ao mesmo tempo, é o momento de vivenciarem a efervescência do coletivo, recuperando os espaços rituais que antes era ocupado por outras instâncias, como a religião, por exemplo (DAYRELL, 2001, p.216).

Para Hermano Vianna, o baile é formado por um sentido de homogeneidade e diferenciação.

É nesse sentido que o baile pode ser visto como um ritual, agregando pessoas, permitindo a experiência de sentir e experimentar em comum, fazendo com que o indivíduo se sinta parte de uma massa humana que se reconhece na música, que gesticula da mesma forma, no mesmo ritmo. O corpo torna-se o protagonista de uma comunicação não-verbal que coloca a sensualidade e os sentidos no centro da festa. É uma forma de catarse de emoções, com um vitalismo que conjuga efervescência e paixão, numa intensificação dos desejos, reforçada pela exposição dos corpos (VIANNA, 1988, p.108).

No entanto, se o funk configura-se como manifestação popular negra, não está imune às disputas simbólicas ante a cultura dominante. Retomando Hall (2003), entre as 
representações do senso comum associadas ao funk, está a construção de um estereótipo que remete à ignorância, à promiscuidade e à criminalidade.

O funk, na medida em que alcançou destaque inusitado no cenário midiático, foi imediatamente identificado como uma atividade criminosa, uma atividade de gangue, que teve nos arrastões e na "biografia suspeita" dos seus integrantes a "contraprova" que comprovaria esse tipo de acusação (HERSCHMANN, 2000, p. $51)$.

Atenta à ambiguidade e à contradição próprias da cultura popular, é preciso destacar, também, que o funk está imerso na lógica da indústria cultural. Como afirma Herschmann (idem), "a mesma mídia que demoniza é aquela que abre espaço nos jornais e programas de televisão" (2000, p.90).

Por outro lado, a própria estigmatização em torno do gênero pode ter contribuído para seu florescimento, possibilitado por um sentimento de compartilhamento de códigos e de identificação.

[O funk] exerce um enorme fascínio sobre um grande número de jovens que parecem ter encontrado nesses grupos sociais, na sociabilidade e nos estilos que promovem formas fundamentais de expressão e comunicação (HERSCHMANN, 2000, p. 20).

Desta forma, como manifestação da cultura popular negra, o funk revela-se em toda sua força e vulnerabilidade. Talvez, o fato mais importante a se destacar é o vigor demonstrado pelo fenômeno em se adaptar e se estabelecer no cenário do consumo cultural, contexto caracterizado pela volatilidade de seus conteúdos. Como "som de preto e de favelado", com todas as incoerências e caráter contestatório de tal qualificação, o funk prossegue como alternativa identitária e afirmativa para muitos dos jovens brasileiros pobres e negros.

Vários jovens dos segmentos populares continuam identificando nesta atividade uma opção, uma via de ascensão social neste país marcado por um modelo sociopolítico e econômico excludente e autoritário. É possível afirmar que o funk, ao lado do futebol e do mundo do crime, apresenta-se como alternativa de vida mais atraente a esses jovens do que se submeter a um estreito mercado de trabalho que lhes impõe empregos "sem futuro", com tarefas massacrantes e monótonas. Este tipo de "carreira" parece promover, em um contexto marcado pela experiência cotidiana árdua, uma difícil sintonia entre as expectativas das famílias e as aspirações juvenis (HERSCHMANN, 2000, p. 256).

\section{Considerações finais}


Mais que um gênero musical, o funk é um estilo de vida para uma parte da juventude brasileira. Estilo de vida este marcado por referências da cultura negra, o que permite classificar o movimento com as manifestações diaspóricas.

Amado e odiado, o funk insere-se no complexo diálogo que vai muito além do jogo dicotômico entre perseguição e resistência, adesão e rejeição.

O que não se pode ignorar é o impacto social e cultural causado pelo funk. O gênero atravessou décadas e hoje é uma das principais forças de sociabilidade e lazer nas comunidades pobres urbanas do Brasil.

No entanto, como expressão de seu caráter híbrido e diaspórico, observam ambiguidades e contradições. O funk que arvora ser "som de preto", é o mesmo funk que perdeu sua conotação de afirmação étnica durante sua trajetória. É o estilo em que, por um lado, as mulheres festejam a liberdade sexual, por outro lado, há afirmação do velho sexismo.

Talvez uma riqueza do funk seja a possibilidade de expressar tais ambiguidades em caráter de pura festa. Um som que quando toca ninguém fica parado ou indiferente.

(Artigo recebido em 26/11/2013, aprovado em 13/12/2013)

\section{Referências}

BAKHTIN, Mikhail. A cultura popular na idade média e no renascimento. São Paulo: Annablume/ Hucitec, 2002.

BAUMAN, Zygmunt. Globalização: as consequências humanas. Rio de Janeiro: Zahar, 1999. BURKE, Peter. Cultura popular na idade moderna. São Paulo: Companhia das Letras, 1989.

CANCLINI, Néstor García. As culturas populares no capitalismo. São Paulo: Brasiliense, 1995.

Culturas híbridas: estratégias para entrar e sair da modernidade.

São Paulo: Edusp, 2006.

CHARTIER, Roger. Cultura popular: revisitando um conceito historiográfico. Revista de Estudos Históricos, vol. 8, n. 16, Rio de Janeiro, 1995.

DAYRELL, Juarez. O jovem como sujeito social. Rev. Bras. Educ. [online]. 2003, n.24, pp. 40-52. ISSN 1413-2478. http://dx.doi.org/10.1590/S1413-24782003000300004.

. O rap e o funk na socialização da juventude. Educação e Pesquisa, v. 28, no 1, p. 117-136, jan.-jun. (2002a).

A música entra em cena: o rap e o funk na socialização da juventude.

Belo Horizonte: Editora UFMG, 2005. 
ESSINGER, S. Batidão: uma história do funk. Rio de Janeiro: Record, 2005.

HALL, Stuart. A identidade cultural na pós-modernidade. Trad. Tomaz Tadeu da Silva e Guacira Lopes Louro. 7 ed. Rio de Janeiro: DP\&A, 2002.

HALL, Stuart. Da diáspora: identidades e mediações culturais. Belo Horizonte: UFMG, 2003.

HERSCHMANN, M (org). O Funk e o Hip-Hop Invadem a cena. Rio de Janeiro, 1997. . Galeras cariocas: territórios de conflitos e encontros culturais. Rio de Janeiro: Editora da UFRJ, 1997.

SÁ, S. P. Funk Carioca: música eletronica popular brasileira?! e-compós, 2007.

SÁ, S. P. Som de preto, de proibidão e tchuchucas: o Rio de Janeiro nas pistas, 2009.

VIANNA, Hermano. O mundo funk carioca. Rio de Janeiro: Jorge Zahar Editor, 1987). . Funk e cultura popular carioca. Estudos históricos, v. 2, n. 6, 1990, p. 244-53. < http://virtualbib.fgv.br/ojs/index.php/reh/article/view/2304/1443 > 